\title{
'From Rotterdam to Rio': Investigating Perceptions of Sporting, Socio-Political and Cultural Developments in Germany between 2000 and 2014
}

\author{
Neal Sutton ${ }^{1} \&$ Joel Rookwood ${ }^{1}$ \\ ${ }^{1}$ Liverpool Hope University, Hope Park, Liverpool, United Kingdom. \\ Correspondence: Dr. Joel Rookwood, Liverpool Hope University, Hope Park, Liverpool, L16 9JD, United Kingdom.
}

Received: June 4, 2015

Accepted: June 19, 2015

Available online: June 24, 2015.

doi:10.11114/ijsss.v3i4.899

URL: http://dx.doi.org/10.11114/ijsss.v3i4.899

\begin{abstract}
This research explores the perceptions of a sample of German nationals towards socio-political, cultural and footballing contexts between periods of the UEFA European Championships in 2000 and the FIFA World Cup in 2014. The examinations of perceptions were obtained through interviews of German football fans from both western and eastern regions, including SV Werder Bremen club officials. The findings suggest that national pride has become an increasingly prominent feature in a unified Germany following the hosting of the 2006 FIFA World Cup. It is also argued here that immigration in German society has positively impacted the German national soccer team. However, there are some recurrent and seemingly problematic issues in German society pertaining to immigration and religious identity. Some fans and officials consider the promotion of national team manager Joachim Löw as a catalyst in the subsequent success of the national team in Rio in 2014, impacting the development of German football from 2000.
\end{abstract}

Keywords: Soccer, fans, Germany, hooligans, immigration, World Cup.

\section{Abbreviations}

Bundesliga - German Football First Division; DFB - Deutcherfußball Bund; DFL - Deutcherfßball League association; FRG - Federal Republic of Germany; GDR - German Democratic Republic; Nato- North Atlantic Treaty Organization; SME - Sporting Mega Events; UEFA - Union of European Football Associations. 'Soccer' and 'football' are used interchangeably in this article.

\section{Introduction}

\subsection{Introduction}

Identity can be thought of as the human capacity to know 'who's who' and hence 'what's what' (Jenkins, 2008: 5). Social identity is a term used in various contexts in the social sciences partly to illustrate individual comprehensions of the self as discrete, separate entities (Sharma and Sharma, 2010a). The construct is often considered to relate to the principles of sameness and differentiation over time and space, sustained through ceremony and ritual (Rookwood, 2012). Individuals negotiate their identities through social interactions, through internal identifications of their public image and through external engagements which others can accept or not - as individual identification emerges within the ongoing relationship between self-image and public image (Jenkins, 2008). Social identity is often considered a fluid rather than static construct, subject to innovation and reconstruction. However, pride can be framed as a more self-conscious emotion (Izard, Ackerman and Schultz, 1999), with experiences of joy often a reflection of what might be perceived as positive engagements (Carver and Johnson, 2011). Identity is a complex construct that is difficult to measure empirically. It is however often thought to be manifest in social life through a myriad of communicative acts, including the use of expressive forms such as clothing and flags, as well as one's body in physical movement and vocalization (Guschwan, 2011). Maguire (2005) and Kraszewski (2008) indicate that sports can symbolize local and national identities. In some socio-political contexts, this is particularly the case through soccer, which can allow opportunities for spectators to collectively reaffirm their own beliefs, values and myths that underlie their cultural identities (Rookwood, 2009a). 


\subsection{Exploration of the Problem}

The development of sports mega events such as the FIFA World Cup has seen such competitions adopt increasing global significance. Host nations invest considerable resources in bidding for, and then staging such tournaments. The widespread cultural and economic consumption of these tournaments can both inform and reflect the growing perception that sports mega events have become recognised as key platforms central to the global cultural economy. Given the significance, complexity and variance associated with these sporting events, there is considerable variation in their reception, interpretation and analysis. Germany has a relatively long and varied history in the staging of global sports events. It has been argued in relation to the hosting of the 2006 World Cup in Germany that national pride was enhanced in connection with an increasing consciousness of national identity (Grix, 2012). The nature and extent of national pride at the 1972 Olympic Games in Munich and the hosting of the World Championships in 2006 has been investigated in comparative contexts (Hallmann, Breuer and Kühnreich, 2013). However, subsequent comparative research is required, notably in light of Germany's triumph in the 2014 World Cup. As with social identity, within football fan culture, attitudes and practises are constantly developing with exposure to contemporary conditions and experiences (Burdsey and Chappell, 1996). This well-established area of research forms one component of this study. In addition however, there is little academic literature which has focussed on the effects of immigration on the German national team, and this work therefore also focuses in part on perceptions of this correlation. There is also a lack of research on the perceived differences of football across what was East and West Germany, regarding football fandom and in particular hooligan perceptions of German nationals. This work therefore is also intended to make a contribution to the knowledgebase in this area.

\subsection{Contemporary German History and German Football}

Germany has experienced waves of immigration during various periods of its history. For example, after the German defeat in World War Two, many Germans fled from the Soviet army, or were expelled from former occupied countries such as Poland and the Soviet Union (Capon, 2012). This led to what could be conceived as evolving geographical entities, with 'refugees' travelling to what became West Germany and East Germany (Salt and Clout, 1976). However, pronounced political and social differences emerged between East and West Germany, particularly from 1949 to 1989. In 1949 two German States were founded: the FRG and the GDR (Huschka, Gerhards and Wagner, 2009). Political and societal differences between East and West Germany became particularly prominent from the early 1960s with the erection of the Berlin Wall. Those differences are considered by Burda (2006) to be related in part to the general economic conditions in East Germany, e.g. private and public capital accumulation, and the nature of economic institutions and technological limitations. More recently however, despite the reunification of Germany in the late 1980s, the overall distinctions in wages between those living in East and West Germany amount to about 25 percent in favour of the latter (Smolny, 2009; Smolny and Kirbach, 2011). Alesina and Fuchs-Schündeln (2007) argue that political German values will converge twenty to forty years after the reunification, although this claim lacks substantiation. Conversely, Kuhn (2012) contends that prevailing differences in political preferences and the perceived experience of inequality in what was East Germany has helped maintain socio-economic and therefore political distinctions from what was West Germany.

Football has remained one of the most popular sports in the world since the late nineteenth century, following its international diffusion, instigated primarily by the British (Giulianotti and Robertson, 2004). It has been argued however, that the growing popularisation of football in Germany from the 1880s occurred largely through the emergence of workers' sports clubs and associations, and not by middle-class initiatives as it may have been elsewhere (Dann, 1996). During the 1930s and 1940s, the Nazi Party manipulated football as a tool to promote their regime (Chadwick and Hamil, 2010). Subsequently, German football underwent notable developments after World War Two. By 1963, the elite league in German football, the Bundesliga, was established and Cologne became the first German champions. Prior to this, the European governing body of the sport (UEFA) was founded in 1954. UEFA created a competition consisting of the league champions of each of the associated European governing bodies of football, known from the 1955-56 season as the European Champions Clubs Cup - and then simply as the 'European Cup' (Holt, 2009). Within that timeframe, the victory in the 1954 World Cup in Hungary was Germany's first landmark in the history of football and of the World Cup. Consequently, it is claimed that many Germans began to regain some sense of national pride, which had been significantly altered by the events of two global conflicts (Empacher, 2001). However, the relationship between the German national team and its citizens or 'fans' remained somewhat strained from the end of the Second World War, and the nation's sporting triumphs were often met with little enthusiasm, even by German football fans, until relatively recently (Capon, 2012). There are perhaps some punctuated exceptions to this rule, most notably the 1974 World Cup victory over rivals Holland. 


\subsection{German Fandom}

The formation of distinctive identities of German football clubs and the evolution of fandom from the 1920s was shaped by various developments. These included the selection of club names and the adoption of distinctive colour combinations linked to certain regions (Merkel, 2007). Research suggests that there were repeated displays of nationalist, chauvinist and racist attitudes often combined with hooligan behaviour in German football, particularly in the 1970s and 1980s, elements of which became visible at the 1988 European Championships. This was thought to have been connected in part to those linked to right-wing and neo-Nazi ideologies (Merkel, 2007). Public consciousness pertaining to the social class of football hooligans, which is often an issue of perception in western contexts towards East German football hooliganism, has been expressed through social science and governmental publications in western Germany (Dennis and LaPorte, 2011). The term 'hooligan' is often thought to be an imprecise legal notion (in the UK, for instance), often with no precise definition in political contexts (Williams, 2002). However, the construct has been presented as episodes of crowd trouble inside and outside football stadiums on match days (Jewell, Simmons and Szymanski, 2014). More specifically, Rookwood (2014) defines a 'hooligan' as an individual who attends football matches with the intention of becoming involved in violence with rival supporters (whether or not $\mathrm{s} /$ he achieves that aim) or a fan who becomes involved in violence (but not other disorder or criminal activity) even if this was not his/her initial aim. Historically, the prevalence of hooliganism in East Germany is thought to relate to an identity crisis and the exposure to challenging social circumstances (Pilz, 1991). Despite some suggestions that football hooligans are predominantly working class (Kerr, 1994), Ek (1996) and Rookwood (2009b) state that West German hooligans span a range of social classes, and claim that there were increases of young men from middle or upper class backgrounds within hooligan groups in the 1990s. However, during the early years of the GDR, it was not until the 1970s and in particular the 1980s that state authorities became concerned about the spread and escalation of football hooliganism amongst populations of young males, notably in East Berlin and Leipzig (Dennis, 2006). This was thought to relate in part to increases in unemployment (McDougall, 2014).

\subsection{The fall of the Berlin wall}

In 1989, after the fall of the Berlin wall, the reunification of Germany influenced various significant political developments in Europe, which helped create the conditions for what effectively became a (re)unification of the continent (Brand et al., 2013). Some argue that the fall of the Berlin Wall (and the subsequent breakup of both the USSR and Yugoslavia) was largely welcomed throughout Western Europe, representing the end of dictatorships, the disintegration of the Eastern Bloc, the triumph of market capitalism, and the end of the Cold War (Berdahl, 2005). The persistence of German pacifism during the Cold War has been examined by scholars, some of whom have argued that any hostilities between NATO and the Soviet Union during this period might have led to a war fought on German soil (Berdahl, 2005). After the reunification of Germany, the Bundesliga was expanded to twenty teams from 1991-1992 and integrated the top two teams from the former top flight in East Germany: Dynamo Dresden and Hansa Rostock (Frick and Prinz, 2006). In addition, the influx of non-nationals had a significant impact on German football. Expanded player migration was facilitated by alterations in European employment law, and in Germany (as with other European leagues including those in England, Spain, Italy, France) the Bundesliga developed into a relatively transnational and even global league. This is thought to have inhibited the development of some local players (Merkel, 2007), a criticism that has been directed at many of other transnational football leagues. Some have suggested that domestic football in Germany became less German and more internationalised therefore, through integrated Europeanisation (Brand and Niemann, 2007).

\subsection{Europeanisation and Football}

Europeanisation can be considered as a term used to describe changes in political processes, through domestic and transnational political developments informed by European integration (Brand and Neimann, 2005). Literature relating to Europeanisation and football often disregards various important political dimensions of the sport, which might be considered more prevalent within globalisation debates (Foer, 2004). However, some authors have tried to establish a link between European integration and the development of football in Europe (Missiroli, 2002). Europeanisation in footballing terms could perhaps have been shaped particularly from 1927, with the introduction of the Mitropa Cup (a tournament which pre-dates the European Cup) a competition which had a twelve-year lifespan, involving clubs competing primarily within the geographic triangle of Vienna, Prague and Budapest (Brand, Neimann and Spitaler, 2013). Some suggest that the increasingly frequent regional and international contact through matches and peer group orientation from this period came to constitute a trans-boundary of central European football (Marschik, 2000). The formation of the Champions League in 1992 (a re-branding of the European Cup) however, is considered to have increasingly prioritised the financial interests of Europe's elite football clubs (Holt, 2009). Nevertheless, the impact of issues pertaining to nationality became embedded in European football with the 'Bosman' case (named after the Belgian footballer John-Marc Bosman) (Brand et al., 2007). As Rookwood and Chan (2011: 899) note (in a football context), 
following the European Court of Justice's Bosman ruling in December 1995: "Restrictions concerning the international freedom of movement were found to contravene the principles outlined in the Treaty of Rome which were strengthened by the Maastricht Treaty. The removal of such restrictions lubricated a transnational European-centred transfer market." The resultant internationalisation of elite leagues such as Germany's Bundesliga, together with the expansion of domestic (and increasingly transnational) broadcasting contracts furthered the global exposure of German football. The Europeanisation of football developed therefore through the expansion of the media and the increased frequency of competitive encounters (King, 2000).

\subsection{Germany's Footballing Immigration}

By opening up the market for players from all other EU countries, this inevitably saw an increase in the number of foreign-born players participating in domestic leagues such as in Germany (Brand et al., 2013). Recently published statistics claim that approximately 2.8 million German inhabitants have a Turkish migrant background for instance, with predominantly low-skilled male labourers filling the German economy's labour demand, particularly from the 1950s and 1960s. Furthermore, after recruitment ceased, family members often settled permanently in the Federal Republic (Diehl and Koenig, 2013). This suggests that these immigrants would have eventually become German citizens or nationals, and their children too, facilitating their theoretical availability for German national teams in sports such as football. Within that timeframe there has been an increasingly significant presence of migrant players within the German squad including Miroslav Klose and Lukas Podolski whom are both of Polish backgrounds, and Mesut Özil and Sami Khedira, both of whom were born in Germany to a Turkish parent or parents (Capon, 2012).

\subsection{The Reformation of German Identity}

Following the 2006 World Cup in Germany, Kersting (2007) claimed that such sports mega events can influence processes related to national identity. A survey showed 61 per cent of the German population demonstrated a sense of belonging, evidenced by the visual practice of covering their houses and cars with the German flag. The success (or otherwise) of such tournaments is often analysed in relation to attendance figures, facilities and socio-economic impacts within the communities (Briedenhann, 2011). A number of authors have highlighted the impact of sports mega events on the host country or cities in terms of enhancing employment and improving public image (Bowdin, Allen and O'Toole, 2006). A 'friendliness campaign', which included a long-term series of co-ordinated campaigns, focused on a creation of a 'feel-good factor' around the tournament and 'fan-centred' approaches to the organisation of the event (Grix, 2012). In addition, Ohmann, Jones and Wilkes (2006) examined the perceptions of 180 Munich residents relating to the impact of the tournament in one of the host cities during the World Cup. The data revealed a collective positivity expressed by residents in urban regeneration areas, also showing an increase in the sense of security within communities. The diplomatic opportunities presented through the hosting of this sport mega event in Germany allowed public figures to champion and project a positive image of their city/country, in order to increase credibility and status on a global stage (Grix and Lee, 2013).

Traditionally, the strength of dominant nations might have been perceived to relate to their ability to win wars, for instance. However, as technology has evolved, power has often shifted in certain contexts from an emphasis on military capacity. This is because physical force is thought to potentially jeopardise part of one's economic objectives and global performance (Nye, 1990). Rather than adopt 'hard power' strategies - such as through military might or economic incentive therefore - the use of indirect forms of power has become considered a more appropriate option for some national leaders to exploit. This relates to the capacity to exert and emulate attractiveness and admiration based on one's actions, in order to entice others - to co-opt others rather than coerce them - which can be referred to as 'soft power' (Nye, 2004). This means that political agendas can be set in order to shape the power preferences of others, via their desire to duplicate your 'soft power resources', namely relating to attractive cultures, desirable ideologies and credible institutions and practices (Nye, 2008). This has been particularly significant in the use and analysis of sports mega events.

\subsection{The Reconstruction of German Football}

West Germany won the 1990 World Cup (competing as a separate nation despite their reunification a year earlier), and Germany won the 1996 European Championships. However, a disappointing campaign at the 2000 European Championships, with defeats to England and Portugal and a failure to qualify from the group stages of the competition, led to widespread criticism of German football. After the 2000 Championships, immediate steps were taken to transform the German national team. A study into the reprisal of German football was conducted (somewhat curiously) by the British House of Commons (2011), which investigated how the DFB and the DFL cooperated after Euro 2000, and addressed a perceived weakness in youth development. The extraordinary congress of the German FA paired a seminal reform for the professional leagues (Chadwick and Hamil, 2010). The first league and the second league were removed from the German FA's jurisdiction, and from 2001-2002 seasons the 36 professional football clubs in these 
divisions constituted themselves as members of the DFL. Subsequently, the DFB effectively became responsible for the development of young footballers up to the age of 14, of whom the most talented typically train once a week at national centres with DFB coaches. From ages 15 to 18, the best young players are nurtured by league clubs and may then be offered professional contracts (British House of Commons, 2011). In the post-2000 era, the DFB and DFL have worked together on developing young players therefore, supported initially by a $€ 40$ Million investment in their programme. Each club in the top two divisions of German football have since been obliged to run a youth academy, one aim of which is to support the future national side (Brand and Niemann, 2005). This is notably different from the British system for instance, in which clubs can sign players from a much younger age, and there is often less emphasis on the performance of the national team, compared to that of the elite clubs of the Premier League (Rookwood and Chan, 2011).

Some researchers therefore, have found that football can develop national pride and shape national identity (Ohmann, et al., 2006), and this study explores these terms in relation to Germany, focusing on a comparison between key events between 2000 and 2014. Chadwick and Hamil (2010) and Brand and Niemann (2005) suggest the developments in German football from 2000 have contributed to positive changes in the national sporting system. This study examines whether the perceptions of fans reflect such sentiment, pertaining especially to German national managers who have contributed to the nation's footballing success. There is a lack of research conducted specifically on the effects of immigration on the German national team since 2000, and in addition therefore, this study explores perceptions of the impacts of immigration on the national team and the perceived socio-cultural climate. Furthermore, some authors have highlighted the problems Germany has experienced with football hooliganism, particularly in East Germany (Dennis and LaPorte, 2011). This study also examines some local perceptions in this regard. This research therefore serves as a comparative examination between East and West Germans in relation to socio-political and sporting views in the twenty-first century.

\section{Method}

\subsection{Methodological Considerations}

A methodology can be considered as the rationale for using a particular research 'recipe', whereas methods might be framed as the 'ingredients of research' (Clough and Nutrbrown, 2002: 32). Based on sociological foundations, this work is underpinned by specific assumptions, and placed in the interpretive paradigm (Sparkes, 1992). Quantitative research can be characterized by human behavioural assumptions, rationalized by evidence which can be investigated to utilize "the deductive logic of the natural sciences" (Horna, 1994: 121). However, qualitative methodologies in sport-related research often focus on a context in which meaning, movement, the self, and experience are inextricably linked, and offer valuable insights towards the objective of scientific knowledge of sport (Bain, 1995). "If researchers are more interested in the thoughts and feelings of people, then quantitative is difficult to quantify, and therefore qualitative data will be more appropriate" (Gratton and Jones, 2010: 33).

\subsection{Interviews}

Various qualitative methods have been utilised in ascertaining and giving voice to perspectives in football contexts. These include participant observation, focus groups and interviews. The use of semi-structured (as opposed to structured or unstructured) interviews in this study allowed for the context of the topic to be revealed, but the flexibility and spontaneity of the process also enabled related lines of inquiry to be pursued (Mason, 2002). Methods such as interviews can facilitate the 'transfer of information' (Marshall, 1998: 328) from the participant to the researcher. Similar approaches have been adopted by Stott, Hutchison and Drury (2001), Brown et al., (2012) and Ohmann et al., (2006), who all based their studies on collecting data about football fans. It is important to note that one of the main procedural weaknesses of the study related to language and communication. Competence in oral communication (speaking and listening) is a prerequisite for success in many areas of social interactions (Morreale, Osborn and Pearson, 2000). Language can be problematic in relation to expressive linguistic components and can reduce the emphasis attached given phenomena (Rookwood, 2009b). This is particularly the case when participants are recruited to studies across different linguistic contexts. When language proved a potential problem in Ohman's study (2006), he used interview schedules which were designed in English and given to native German speakers to translate, before the interviews took place. All participants in this research however were recruited and agreed to speak only in English during interviews. All participants were selected in part because of their fluency in English, although German was their first language. A 'gatekeeper' was used for the recruitment of German national football fans. This term was employed by Sugden (2002: 111) who used specific soccer supporters to gain access to other fans in his study.

\subsection{Participant Selection Criteria and Data Collection}

All the research was conducted in Germany between September 2014 and March 2015. In order to gain meaningful data, interviewees were recruited relative to specific conditions through the formulation and implementation of participant 
selection criteria. This helped ensure a degree of contemporary knowledge on key issues, with respondents therefore more likely to appreciate the context of their experiences and perspectives. Participants were selected who were considered to have an in-depth understanding of German football, the importance of which is noted by Rookwood (2009b). This study was based on the perceptions of nine German national fans and club personnel, from whom seven were from West Germany (of which two were actually SV Werder Bremen club officials) and two other respondents were from East Germany. The sample size was deliberately kept relatively small to allow for a degree of depth of response from each interviewee. Each of the fans (and indeed the club officials) supported their respective geographically local club, and the German national soccer team. Such a correlation is commonplace, but by no means taken for granted, as there are many cases of what might be perceived as soccer separatism in European football, with some fans of FC Barcelona, Liverpool and Swansea City for instance, often not choosing not to support the national team of the country in which their respective teams are based (Rookwood, 2012). One important aspect of the criteria for selection here was that all participants must have been over the age of 25 at the commencement of the study in 2014, as it was important they were old enough to have formed memories of the Euro 2000 championships.

\subsection{Data Collection and Analysis}

Participants were asked to offer their opinions on specific topics, which were determined after undergoing a critical review of relevant literature. The interpretation of the data was conducted through a thematic analysis. This is a method for identifying and analyzing patterns or themes within the data. The findings were subject to minimal organization and reduction however, with the data presented in rich detail (Braun and Clarke, 2006; Wilkinson, 2000). The participants' responses follow in the subsequent section, using the following key: All the evidence was collected by interviews (I), followed by (W) for a West German and (E) for an East German (E), and (F) for fan and (O) for club official, lastly followed by a number to differentiate between the interviewees of the same type, e.g. IWF1.

The findings discussed here are not intended to be considered as representative of all German supporters. As Bryman notes: "brief conservations, snippets from unstructured interviews... are used to provide evidence of a particular contention. There are grounds for disquiet in that the representativeness or generality of these fragments is rarely addressed" (1988: 77). This highlights the researcher's responsibility to strive to present, discuss and analyse data relative to the context in which it was delivered. It was also important to employ appropriate participant selection policies, to ensure the findings were as representative as possible of the culture being described. However, it is important to note that this process also incorporated selective practice. This methodological limitation therefore could not be fully mitigated. Selecting interviewees, a process undertaken in this instance by the first author, primarily through a gatekeeper, involves making subjective choices, limiting other possibilities. Such decisions may have limited the generalisablity of the research; importantly however, this also enhanced the manageability of the work.

\section{Results and Discussion}

\subsection{Identity and Pride in German Football}

When the interviewees were questioned on their respective perceptions of identity, they offered views and elaborated with a degree of detail. One can deduce that this highlights a degree of consciousness about the correlation between sport and social identity amongst the respondents. Jenkins (2008) suggests that sport can symbolize both local and national identities. Soccer allows opportunities to collectively reaffirm beliefs that underlie cultural identities (Rookwood, 2009b). Similar, contextualized sentiments were offered in this work. For instance, one participant explained: "Identity is finding a happy place where we want to stay...FC Hansa Rostock for me. I'm a fan and identify myself with the club with my season-ticket" (IEF1). Another participant stated that the promotion of sporting teams can reaffirm identity. Participants were also asked for their assumptions of the definition of pride. Izard et al. (1999) suggest that in a sporting context, pride can be considered as a self-conscious emotion, a reaction to one's self - and sporting teams represent communities and countries, as they compete for glory (Guschwan, 2011). The following participants claimed: "to be proud of your nation, your country, your language and maybe your soccer team, that's pride for me" (IWF3). However, another response provided a view of pride with a historical frame of reference in a German context: "It's a strange sentence to say 'I'm proud to be German'. I'm proud of what we did after the war, with the reconstruction of Germany and the peaceful revolution we had with Eastern Germany, unlike the revolutions in Ukraine and Russia today" (IWO1). Similar comparisons with other socio-political entities and rivalries proved common in this research. Regarding national pride and football, Empacher (2001) suggests that Germans regained post-war national pride partly through football. However, one respondent offered the following contention: "I don't know if it [football] helped, it was just after the War. In my opinion it didn't because it would take a couple of generations for us to not be guilty of what happened" (IWF3). Another respondent suggested that pride was affected because of the World Cup win in 1954; however only for a limited period: "It [the 1954 World Cup win] was very good for Germans and the pride of the country. They had good things to think about with the win, instead of the War, but I don't think they forgot about it 
all together, just for the moment. Most had to rebuild their houses which were destroyed" (IWF4).

Participants were also asked if the hosting of the World Cup in 2006 helped redevelop a common identity in Germany, as Capon (2012) suggests. One participant stated: "In 2006 it was good and other people were talking to me and said 'it's fantastic in Germany' and said we are 'nice people'. Everyone was friendly and everyone who came here enjoyed it, so it was good for us" (IWF4). Hicks (2014) refers to the enthusiastic displays of symbolism by German soccer fans, who were a visible presence across many German cities. When questioned about the connected symbolism around the 2006 World Cup, one respondent stated: "Nearly every car had a little flags on their windows. It was no longer stupid or bad to be proud of my country" (IEF1). When participants were asked about their views on German national identity, comparing the victory in the 2014 World Cup with hosting the World Cup in 2006, one participant stated: "Most said after winning the World Cup, 'Germany is World Cup winner!' The first time after the Second World War that we are proud of our team, more so than 1990 [the World Cup in Italy] and 1954 [the World Cup in Switzerland]" (IWO1). However, one participant differentiated between the two events, stating: "The win of the World Cup was a competition success and made us proud of the team. In 2006 we were proud to be Germans and show the world, we are no monsters" (IEF1).

\subsection{The Reconstruction of German Football}

As previously stated, the DFB is now responsible for the development of young footballers and the best young players in Germany - and the DFB and DFL effectively collaborate on developing players throughout Germany (Brand and Niemann, 2005; Chadwick and Hamil, 2010). When participants were asked about their perceptions on the changes of German football post-2000, one respondent stated: "The German federation funded everywhere and picked the best players from about 300 clubs in Germany. The best players around those areas were given additionally training sessions, once a week and this was for children aged 11-14" (IWO2). In relation to German football before the Euro 2000 championships, one participant stated: "In the "90s you had the notion that German youth players are not developed in any other things like running, and we had a national team that couldn't play with the ball" (IWF2). Within the period from 'Rotterdam to Rio', i.e. from 2000 to 2014, there were conceptual and practical changes in management towards the German national football team. Participants were asked on their views on these changes and what the individual managerial impacts had on the German national team. One participant claimed that the transition from national team managers Jurgen Klinsmann to Joachim Löw was a pivotal point in the German national team's victory in Rio, with another respondent stating: "Löw found a good way with players like [Miroslav] Klose, [Philipp] Lahm, [Bastian] Schweinsteiger, [Lukas] Podolski. The new generations came from the academies that started their career with Klinsmann and in 2014 finals. Löw chose a good mixture of talents" (IWO1). Other participants stated that the national team played like a club team: "Klinsmann was a motivator and Löw had already developed the football style. In 2006, Germany's good football begun, because Löw worked with the team that played like a club" (IWF2). Another respondent stated that "In 2000 it was fighting football and we defended and wait for penalties. Now we play attractive offensive football like the Brazilians, with discipline and teamwork. We play the best team not the best players. Years ago [Stefan] Kießling was the best striker but he didn't fit in the team" (IEF1). Another participant suggested that the reason that players did not fit in the team system was because of the framework set by the respective manager's playing system: "Klinsmann and especially Löw looked for the right players to fill their guidelines. A coach won't look for player and develop a guideline. You have a guideline and fill it with players. Sometimes players don't get into a team, because they don't fit those guidelines" (IWF3).

\subsection{Immigration and German Football}

According to Capon (2012) Germany has experienced increased immigration in recent years. When participants were asked if immigration has shaped German society, there was a suggestion that social problems have become apparent concerning the increase in the number of migrants, as one respondent stated: "When you're with people in a social way, they say it's bad. In Dresden with the PEGIDA (Patriotic Europeans against the Islamisation of the West), like 18,000 people in Dresden demonstrating against Islam, with $2.4 \%$ of Islamics in Dresden. Some think immigrants want to steal our jobs, women or whatever" (IWF1). Protests in Dresden were also referenced in another participant's response: "There was a huge demonstration against Islam and they haven't got many Islamics in Dresden. It's a paradox, so the less foreign influence you have, the more people are frightened" (IWF2). A possible motive behind the protest was suggested through the following response: "In the big cities you have 80-90\% immigration. For Germans it's tough in their own country because you're foreign in your own country" (IWF3). However, in contrast the majority of participants claimed that immigration was not a problem within society. For instance: "It's good because the people from abroad have made good things in this country. You see it in every town you go to, and the new people bring in new things" (IWF4). Furthermore, another interviewee offered this argument about the impact of immigration: "We have people and players from different roots and it opened Germany to other countries and to include them in our identity" (IWO2). 
In relation to the Bosman ruling and the changes in European football, one participant offered the following perspective: "The Bosman ruling was the worst thing to happen to European football, young talents were neglected for years because it was cheaper to get foreign players" (IEF2). This response partly reflects the findings of Brand et al. (2013), who argue that the Bosman ruling opened up the market for foreign players from EU countries to gain employment in the Bundesliga. However, the negativity expressed towards the changes in the demographics of players (not to mention fans) in elite European leagues such as the German Bundesliga, facilitated through the Bosman ruling and other processes which have lubricated the transnational advancement of domestic leagues in Europe, have often been overlooked by academics and those responsible for governing these leagues, as Rookwood and Chan (2011) argue. When the participants were asked how immigration has affected the German national team, and if it might have impacted their 2014 World Cup campaign, one respondent stated: "The Polish of Podolski and Klose and the Turkish of Özil, Mustafa, Gündoğan and Khedira. So every country brings good things, mentality, and without them I don't think we would have won the World Cup in Rio" (IWF4). Indeed, Sami Khedira, Miroslav Klose and Mesut Özil alone contributed five of Germany's eighteen goals en route to winning the 2014 World Cup. Similarly, another participant argued: "Foreign footballers have been in the game culture of the Germans. Technically, players have shown that success cannot be achieved only by strength and discipline. The integration of foreign cultures has strengthened the German national team, like in 2014 when we won the World Cup with these players" (IEF2).

\subsection{German Division in Socio-Political, Cultural and Sporting Issues}

When participants were asked for their views on the socio-political issues within and between what was East and West Germany, one respondent stated: "You can earn more in the West. Lots of people say the East has friendly people but it's unfair that they don't get as much money. The wall isn't there but in the minds of some people it is" (IWF4). This suggests that political and societal differences between East and West Germany are perceived by some to still exist, a lingering legacy perhaps of the Berlin Wall. Kuhn (2012) claims that there is a widely held perception that wages are higher in what was West Germany compared to East Germany, even long after Germany's reunification. Related to this, one participant suggested: "When you go to Eastern, rural areas you see differences, rather than the cities. There's a lower salary in the East and unemployment is down to the state in the East. However politically it's similar, there is a small difference" (IWF5). In addition, another respondent shared this view: "There's no young person in Eastern Germany and everyone moves to the West, for better jobs and education. There is nothing to do in the rural part of East Germany. No industry, no nothing" (IWF3). However another participant stated that the differences in West and East Germany have changed since the fall of the Berlin Wall: "After ' 89 a lot of young people went from Eastern Germany to Western Germany. In my opinion it has stopped, some of the West go to the East. You see it in some cities, Leipzig, Dresden which are good culture-full, life-full cities now in Eastern Germany, the East is catching up but it will take many years" (IWO2). Participants also made reference to the economic climate, claiming that the higher taxation of West Germans has helped to modernise the economy in the East: "We still pay reconstruction tax. In East Germany now you have new infrastructure. We are one country now so we should all have good things" (IWO1). Klüsener and Goldstein (2014) have noted that many aspects of everyday life in western and eastern Germany have been converging in the years since the fall of the Berlin Wall. However, Kuhn (2012) claims that there are prevailing inequality perceptions between East and West Germans. The findings from this sample seem to concur with both positions. Indeed, the evidence presented in this study suggests that although various socio-political differences are still perceived to be apparent in this context, the similarities are perhaps becoming more evident in contemporary Germany.

When the interviewees made reference to what they considered to be the political and economic distinctions between what was West Germany and East Germany, many offered sporting examples to contextualise their responses. In relation to football fans for instance, one respondent stated: "In the Bundesliga it's not a problem but deeper it is a problem. Teams from the East who have very hard supporters throw at other supporters and they've got fireworks. It's very hard to get out of Eastern stadiums without getting hit. They're a lot that are working less, and you need a release if you're not happy" (IWF4). However, a participant from eastern Germany claimed that hooligan acts were more prominent in the west: "Socialization in the groups reflects the economic and social situation simultaneously. Football is a valve to drain anger against policies and the state. In the West, the fan groups form their very own subcultures and direct their frustrations against other fan groups" (IEF2). However, another interviewee suggested that football hooliganism is prevalent across the country: "In West Germany you have hooliganism as well, with Cologne and groups in Hamburg; it's a problem in both East and West" (IWF2). Another participant claimed that the police response and media coverage helps explain why hooliganism occurs: "There aren't differences, it's just that Eastern clubs are more often in the news. If you go to a Western match in the third and fourth league, there is violence but not a lot, but it's more policed in the Bundesliga and no one is really doing much. However there are more Eastern teams in the third and fourth league so they get more attention" (IWF5). These perceptions are perhaps unsurprising, as the impact of media coverage and police response has been noted in other fandom contexts. For instance, as Sugden (2002) suggests, 
disproportionate and overzealous policing, together with sensationalist media coverage, can broadcast the problem, effectively advertising football stadia as sites to engage in violence. Publicising disorderly activities in a football context can exacerbate hooliganism therefore, reinforcing and even glamorising hooligan behavior. Conversely, fans who might be disinclined to engage in hooliganism might be dissuaded from attending matches, which can concentrate the problem, and the demographic of football support (Rookwood, 2014).

\section{Conclusion}

The aim of this paper was to examine specific perspectives pertaining to German socio-political, cultural and sporting contexts between the events of the European Championships ('Rotterdam') in 2000 and the World Cup ('Rio') in 2014. Germany has achieved notable success in international football, with a record equalling three European Championships, and four World Cups (a record second only to Brazil, who have five). The achievements of the German national football team, and the significance of domestic clubs in Germany (in terms of both national and international success), has shaped the connections between football and social identity. The 1954 and 1974 World Cup victories (particularly the former) were considered by the respondents in this research to have only had a short-term impact on pride and national identity. It was also suggested by some here that the World Cup victory in 2014 did not have the same effect on German pride compared with the hosting of the World Cup in 2006. Staging the world's most prestigious football mega event, with all the associated economic, political and socio-cultural investments, was perceived by some interviewees here to differ to the experience of winning a World Cup held in another continent. The findings from this small sample therefore, might lead to the contention that perhaps ultimate victory is not always the key determinant of national pride and social identity in football contexts - at least in the German case. Performances and results matter in sports mega events, particularly from the perspectives of the hosts. Six of the twenty World Cups to date have been won by the host nation. South Korea's surprise fourth-place finish as co-hosts of the 2002 World Cup gave rise to changes in the international perceptions of Korean football; conversely, South Africa's failure to qualify from the group stages as hosts of the 2010 World Cup served as another reminder of the lack of African success at this stage - as no African team has ever reached a World Cup semi-final (Briedenhann, 2011).

Perhaps soft power is most clearly manifest and attained in such contexts when sporting performances and results are 'notable', but where sporting dominance is not necessarily achieved. Participants suggested that the hosting of the World Cup contributes to the feeling of a common identity among German citizens. This notion has also been put forward by Holston (2014) who suggests that the World Cup win in 2014 only reflected pride towards the national team. It is clear that some supporters and German nationals feel that national pride was strengthened within the context of a unified state when Germany hosted the 2006 World Cup. This might be in stark contrast to the prevailing 'national guilt' which engulfed Germany following the Second World War. If the 1936 Olympics staged in Berlin is often framed as the 'Nazi Olympics', and the 1972 Games is readily associated with terrorism, the 2006 football World Cup could be framed as a counterpoint for sports mega events hosted in Germany. Such interpretations can be linked to the correlation between sport, soft disempowerment and soft power (Brannagan and Giulianotti, 2014). Perhaps not winning the 2006 tournament offered a useful frame of reference in this respect (Germany were beaten having conceded goals in the final minutes of extra time during the semi-final against eventual winners Italy in Dortmund). Therefore, we might be able to see the perceived impact of successfully hosting a sporting event (and the contributory investment of the German people), and the effect of this tournament on national pride and identity, which perhaps superseded the value of the ultimate victory that eluded them, but for which Germans are often readily associated with in international soccer.

In relation to the German national team's development from Rotterdam to Rio, it was suggested here that Joachim Löw was the catalyst in the development of the German World Cup winning team, once he took over from Jurgen Klinsmann. Furthermore, various participants suggested that developments in German football post-2000, including the work of the DFB and the DFL, contributed to the advancement and success of young players in the national team under Klinsmann and Löw. This finding reflects the work of Chadwick and Hamil (2010). Regarding the impact of immigration in German society, it was suggested here that the discrimination of immigrants is currently manifest more so in religious terms, namely in respect to Islamophobia. However, despite references to some negative views here, most claimed that there is a growing acceptance of the integration of those representing other cultures, which was considered here to be positive development of German society. Within a footballing context, it is widely suggested that immigration has had a very positive impact on the German national team in recent years, which it was claimed here has been a catalyst to the success at the 2014 World Cup in Rio. Perhaps football can be considered a contextual tool to undermine racist attitudes and help people sense the benefits of migration therefore.

Furthermore, regarding the conceptualized differences between what was East and West Germany, economic, political and cultural discrepancies are thought to exist, and the findings here suggest that in the future, the experience of further equity in socio-political terms would help reduce the prevailing cultural differences (and related sense of injustice) between the two. Alesina and Fuchs-Schündeln (2007) claim that political values will converge twenty to forty years 
after the reunification, however, this timeframe perhaps seems unlikely, as the distinctions between East and West still appear pronounced in some respects, at least in the opinion of the respondents in this research. In relation to German soccer fan culture, participants gave contrasting distinctions and therefore the findings were inconclusive. The notion that East German football fans are more prone to hooligan behavior has been suggested, because of the collective fan anger towards policies within the GDR, and due to the relatively high levels of unemployment in eastern Germany (McDougall, 2014). However, participants suggested that inadequate policing in the lower leagues of German football allowed for supporters of both Western and Eastern teams to engage in acts of violence. However, eastern teams are more likely to feature in the media in this respect. It could be argued that the approach and degree of media coverage will help shape public consciousness in this respect.

Finally, reflecting the work of Engert (2010), it is claimed in this paper that the post-war guilt associated with being German has started to evaporate, as many Germans begin to look forward, rather than backward. This mentality is perhaps shaped by the economic and political significance of contemporary Germany in European terms (Dustmann et al., 2014), in addition to Germany's sporting and cultural achievements. It is important to note that this research was subject to a number of limitations. For example, the work undoubtedly reflected a lack of balance, with eastern German participants relatively underrepresented. This highlights the potential difficulties of recruiting subjects for research of this nature. As the majority of the respondents in this research were of West German origin, the data is likely to be skewed therefore, and yet this yields valuable lessons for future research. In addition to the methodological challenges already outlined, the paper did not give voice to fan opinion on what is thought to be one of the main contributions of the 2006 World Cup, namely the widespread use and popularization of fan zones. These fan parks had not been introduced at preceding World Cup tournaments, where hooliganism had often been prevalent, partly as a consequence of the lack of facilities for fans (Rookwood, 2009b). Following a trial in one of the locations at the 2004 European Championships in Portugal, every venue at the 2006 World Cup in Germany had a fan zone. Matches were broadcasted on 60-metre screens in these temporarily erected parks, under which stages showcased musical and other carnivalesque and cultural forms of entertainment between matches, with fans encouraged to congregate around the stage. The proposed rationale for these fan parks was to monitor fan conduct, and offer supporters opportunities to socialise collectively in a designated space, in the hope that this would discourage deviant behaviour. These parks were largely successful in diffusing deviance and disorder, and the German model here also reflects changing approaches and attitudes towards modern football fans. Further research is required therefore, focusing on football fandom and hooliganism in Germany for future competitions, both at club level and at mega events. The 2016 European championships to be held in neighbouring France offer an ideal opportunity for subsequent research. Further work is also required pertaining to the nature and impact of the ideological, political and socio-cultural similarities and differences between eastern and western Germany.

\section{References}

Adams, P. (2013). Fans, the Bundesliga and the standing room debate. A Study of the German football stadium experience. Unpublished MA thesis.

Alesina, A., \& Fuchs-Schündeln, N. (2007). Good-bye Lenin (or not?): the effect of communism on people's preferences. The American Economic Review, 97, 1507-1528

Bain, L. L. (1995). Mindfulness and subjective knowledge Quest, 47, 238-253.

Bordeau, J. (2010). Xenophobia: The Violence of Fear and Hate. New York: The Rosen Publishing Group.

Bowdin, G., Allen, J., \& O’Toole, W. (2006). Events Management. 2nd Ed. London: Elsevier.

Brand, A., \& Niemann, A. (2005). The Societal/Trans-national Dimension of Europeanisation: The Case of German Football, Queen's Papers on Europeanization, 2.

Brand, A., \& Niemann, A. (2007). 'Europeanisation in the Societal/Trans-National Realm: What European Integration Studies Can Get Out Of Analysing Football', Journal of Contemporary European Research, 3(3), 182-201.

Brand, A., Neimann, A., \& Spitaler, G. (2013). The two-track Europeanisation of football: EU-level pressures, transnational dynamics and their repercussions within different national contexts, International Journal of Sport policy and politics, 3(3), 182-201.

Brannagan, P. M., \& Giulianotti, R. (2014). Qatar, global sport, and the 2022 FIFA World Cup. In Grix, J. (ed.), Leveraging Legacies from Sports Mega-Events. Basingstoke, UK, Palgrave, 33-45.

Braun, V., \& Clarke, V. (2006). Using thematic analysis in psychology. Qualitative Research in Psychology, 3(2), $77-101$.

Briedenhann, J. (2011). Economic and tourism expectations of the 2010 FIFA World Cup - a resident perspective. 
Journal of Sport and Tourism, 16(1), 5-32.

British House of Commons. (2011). Football governance, Seventh report of session 2010-2012. Culture, Media and Sports Committee. 1, 88-89.

Brown, L., Richards, S., \& Jones, I. (2012). Sojourner perceptions of the St George Cross flag during the FIFA 2010 World Cup: A symbol of carnival or menace? International Review for the Sociology of Sport, 49(1), 102-120.

Bryman, A. (1988). Quantity and Quality in Social Research. London: Routledge.

Burda, M. C. (2006). Factor Reallocation in Eastern Germany after Reunification. American Economic Review. 96(2), 368-374.

Burdsey, D., \& Chappell, R. (1996). Solders, sashes and shamrocks: Football and social identity in Scotland and Northern Ireland, In, Sport, identity and Ethnicity. (Ed. J. MacClancy) Oxford: Berg, 181-199.

Capon, B, C. (2012). It is about the flag on your chest! Footballers with Migration Background in the German National Football Team. A matter of inclusion? An Explorative Case Study on Nationalism, Integration and National Identity. University of Oslo.

Carver, S. C., \& Johnson, L. S. (2011). 'Authentic and Hubristic Pride: Differential Relations to Aspects of Goal Regulation, Affect, and Self-Control. Journal of Research in Personality, 44(6), 698-703.

Chadwick, S., \& Hamil, S. (2010). Managing Football: An International Perspective. London: Butterwork-Heineman.

Clough, P., \& Nutbrown, C. (2002). A Student's Guide to Methodology. London: Sage.

Dennis, M., \& La-Porte. (2011). State and Minorities in Communist East Germany. London: Berghahn Books.

Dennis, M. (2006). Soccer hooliganism in the German Democratic Republic. In: Tomlinson, Alan; Young, Christopher (eds.), German Football. History, Culture, Society. London: Routledge, 52-72.

Diehl, C., \& Koenig, M. (2013). God can wait - new migrants in Germany between early adaptation and religious reorganization. International Migration, 51(3), 8-22.

Dustmann, C., Fitzenberger, B., Schönberg, U., \& Spitz-Oener, A. (2014). From sick man of Europe to economic superstar: Germany's resurgent economy, Journal of Economic Perspectives, 28(1), 167-188.

Ek, R. (1996). Hooligans: Facts, background information, Analyses, Worms: Coventry: Cicero.

Empacher, C., Hayn, D., Schuberts, S., \& Schultz, I. (2001). Analysis of the impact of the financial gender role change for environment awareness and behaviour - Institute for Social Ecological Research. Frankfurt.

Engert, S. (2010). A case study in 'atonement': Adenauer's Holocaust apology. The Israeli Journal of Foreign Affairs, 3(4), 111-122.

Foer, F. (2004). Soccer Vs. McWorld. Foreign Policy, 140, 32-39.

Frick, B., \& Prinz, J. (2006) Crisis? what crisis? Football in Germany. Journal of Sports Economics, 7(1), 60-75.

Giulianotti, R., \& Robertson, R. (2004). The globalization of football: a study in the glocalization of the 'serious life'. The British Journal of Sociology, 55(4), 545-568.

Gratton, C., \& Jones, I. (2010). Research Methods for Sport Studies. New York: Routledge.

Grix, J. (2012). Image leveraging and sports mega-events: Germany and the 2006 FIFA World Cup. Journal of Sport and Tourism, 17(4), 289-312.

Grix, J. (2012). 'Image' leveraging and sports megaevents: Germany and the 2006 FIFA World Cup, Journal of Sport \& Tourism 17(4), 289-312.

Grix, J., \& Lee, D. (2013). Soft power, sports mega-events and emerging states: The lure of the politics of attraction. Global Society, 27(4), 521-536.

Guschwan, M. (2011). Fans, Romans, countrymen: soccer fandom and civic identity in contemporary Rome. International Journal of Communications, 5, 1990-2013.

Hallmann, K., Breuer, C., \& Kühnreich, B. (2013). Happiness, pride and elite sporting success: What population segments gain most from national athletic achievements? Sport Management Review, 16(2), 226-235.

Hicks, M, G (2014). Soccer and Social Identity in contemporary German film and media, Pittsburgh: University of Pittsburgh Press.

Holston, J. (2014). Come to the street! Urban protest, Brazil 2013. Anthropological Quarterly, 87(3), 887-900. 
Holt, M. (2009). UEFA, Governance, and the control of club competition in European Football, Football Governance Research Centre. University Of London, 1.

Horna, J. (1994). The Study of Leisure. Oxford: Oxford University Press.

Huschka, D., Gerhards, J., \& Wagner, G. (2009). Naming differences in divided Germany. Names, 57(4), 208-228.

Ismer, S. (2011). Embodying the nation: Football, emotions and the construction of collective identity. Nationalities Papers, 39(4), 547-565.

Izard C, E., Ackerman B. P., \& Schultz D. (1999). Independent emotions and consciousness: Self-consciousness and dependent emotions. In: Singer JA, Singer P, (Eds). At Play in the Fields of Consciousness: Essays in honor of Jerome L. Singer. Lawrence Erlbaum Associates, Inc.; Mahwah, NJ, 83-102.

Jenkins, R. (2008) Social identity; Third Edition, Routledge: London.

Jewell, R., Simmons, R., \& Szymanski, S. (2014). Bad for Business? The Effects of Hooliganism on English Professional Football Clubs. Journal of Sports Economics, 15(5), 429-450.

Kerr, J. (1994). Understanding Soccer Hooliganism. Buckinghamshire: Open University Press.

Kersting, N. (2007) Sport and National Identity: A Comparison of the 2006 and 2010 FIFA World Cups, Politikon: South African Journal of Political Studies, 34(3), 277-293.

Klüsener, S., \& Goldstein, J. (2014). A long-standing demographic East-West divide in Germany. Population, Space and Place.

King, A. (2000). Football fandom and post-national identity in the New Europe. British Journal of Sociology, 51(3), 419-442.

Kraszewski, J. (2008). Pittsburgh in Fort Worth: Football bars, sports television, sports fandom, and the management of home. Journal of Sport and Social Issues, 32, 139-157.

Kuhn, A. (2012). Inequality perceptions, distributional norms, and redistributive preferences in East and West Germany. German Economic Review, 14(4), 483-499.

Macefield, R. (2004). How to specify the participant group size for usability studies: A practitioner's guide. Journal of Usability Studies, 34-45.

Magoun, F. (1942). Il Gioco del Calcio Fiorentino, Italica, 19(1), 1.

Maguire, J. (2005). Power and Global Sport: Prestige, Emulation and Resistance. New York: Routledge.

Markula, P., Grant, B. C., \& Denison, J. (2001). Qualitative research and aging and physical activity: Multiple ways of knowing, Journal of Aging and Physical Activity, 9(3), 245-264.

Marschik, M. (1998). MITROPA: Representations of Central Europe in Football. International Review for the Sociology of Sport, 36(1), 7-23.

Marshall, G. (1998). The Oxford Dictionary of Sociology. Oxford: Oxford University Press.

Mason, J. (2002) Qualitative Researching. London: Sage.

McCracken, G. (1988). The Long Interview. Newbury Park, CA: Sage Publications.

McDougall, A. (2014). The People's Game: Football, State and Society in East Germany. Cambridge: Cambridge University Press.

Merkel, U. (2007). Milestones in the development of football fandom in Germany: Global impacts on local contests. Soccer and Society, 8(2-3), 221-239.

Miller, R. L., \& Brewer, J. D. (2003) The A-Z of Social research: A Dictionary of Key Social Science Research. London: Sage.

Missiroli, A. (2002) European football cultures and their integration: The 'short' twentieth century'. Culture, Sport Society, 5(1), 1-20.

Mittag, J., \& Legrand, B. (2010). Towards a Europeanisation of football? The history of the UEFA European Football Championship. Soccer and Society, 11(6), 709-722.

Nye, J. (1990). Soft power. Foreign Policy, 80, 153.

Nye, J. (2004). When hard power undermines soft power. New Perspectives Quarterly. 21(3), 13-15.

Nye, J. S. (2008). Public diplomacy and soft power. The ANNALS of the American Academy of Political and Social 
Science, 616(1), 94-109.

Ohmann, S. Jones, I , \& Wilkes, K. (2006). The Perceived social impacts of the 2006 football World Cup on Munich residents, Journal of Sport and Tourism. 11, (2), 129-152.

Özsoy, S. (2011). Use of new media by Turkish fans in sport communication: Facebook and Twitter. Journal of Human kinetics, 28(1), 165-176.

Pilz, G, A. (1991). Escalation of violence in connection with the Fussbalgeschehen. Research Report of the Police Staff College, 3, 114-129.

Rachmann, G (2002). Passion, pride, profit. Economists, 363(8275), 3.

Rookwood, J. (2009a). Social Development in Post-conflict Communities: Building Peace through Sport in Africa and the Middle East. Berlin: VDSM Verlag.

Rookwood, J (2009b). Fan Perspectives of Football Hooliganism. Defining, Analysing and Responding to the British Phenomenon. Berlin: Verlag.

Rookwood, J. (2012). We're not English we are Scouse!' Examining the identities of Liverpool Football Club supporters. In, Sport and Social Identity: Studies from the Field. J. Hughson, C. Palmer and F. Skillen (Eds). New York: Edwin Mellen Press. 95-120.

Rookwood, J., \& Chan, N. (2011). The 39th Game' - Fan responses to the Premier League's proposal to globalise English football. Soccer and Society, 12(6), 897-913.

Rookwood, J. (2014). Hooliganism. In, Encyclopaedia of Social Deviance. (Eds. H. Copes and C. Forsyth). Thousand Oaks, CA: Sage, 347-351.

Salt, J. and Clout, H. (1976). Migration in Post-War Europe: Geographical Essays. Oxford: Oxford University Press.

Sharma, S., \& Sharma, M. (2010). Self, social identity and psychological well-being, Psychological Studies, 55(2), $118-136$,

Smolny, W., \& Kirbach, M. (2011). Wage differentials between East and West Germany: are they related to the location or to the people? Applied Economics Letters, 18(9), 873-879.

Smolny, W., (2009). Wage adjustment, competitiveness and unemployment - East Germany after unification. Journal of Economics and Statistics. 229/23, 130-145.

Sparkes, A. (1992). The paradigms debate: An extended review and a celebration of difference. In Research in Physical Education and Sport: Exploring Alternative Visions. (Ed. A. Sparkes). London: Falmer Press, 9-61.

Stott, C., Hutchison, P., \& Drury, J. (2001). Hooligans' abroad? Inter-group dynamics, social identity and participation in collective 'disorder' at the 1998 World Cup Finals. British Journal of Social Psychology, 40(3), 359-384.

Sugden, J. (2002). Scum Airways. Edinburgh: Mainstream.

Tsang, S., Hui, E., \& Law, B. (2012). Positive Identity as a Positive Youth Development Construct: A Conceptual Review. The Scientific World Journal, 20(12), 1-8.

Wilkinson, S. (2000). Women with breast cancer talking causes: comparing content, biographical and discursive analyses. Feminism and Psychology, 10(4), 431-460.

Williams, J. (2002). Who you calling a hooligan? In, Perryman, M. (Ed.) Hooligan Wars, Causes and Effects of Football Violence. London: Mainstream, 37-53.

\section{$(\mathrm{cc}) \mathrm{BY}$}

This work is licensed under a Creative Commons Attribution 3.0 License. 